\section{BIRDS AND BUTTERFLIES}

\author{
By Dr. C. B. WILLIAMS \\ Rothamsted Experimental Station
}

$\mathrm{T}$ WE extraordinary mimetic resemblances which exist between certain apparently edible species of insects and other distasteful species, which are found in the same neighbourhood, reach their highest development in the Rhopalocera or butterflies. The resemblances are purely external and frequently confined to the upper surfaces of the wings only. They are obviously meant to deceive an eye.

If this mimicry has been brought about by natural selection of smaller or larger variations because they are of survival value to the mimics, there must be some enemy whose eye is deceived, and further, in view of the perfection of many of the resemblances, it must be sometimes not deceived by the less perfect resemblances.

Undoubtedly the chief death-rate of butterflies is in the egg, caterpillar and chrysalis stage, but these resemblances which we are now considering are in the adults, so that we have to search for an enemy which can exert a considerable selection pressure in the short period between the emergence of the butterfly from the chrysalis and the time that most of its eggs are laid; for after this latter no selection is of survival value to the race.

We need, therefore, a sharp-eyed predator which is active by day and which sees the butterflies when their upper surfaces are exposed, that is, probably when in flight. Birds are the obvious choice, but when the suggestion was first critically examined it was found that the evidence of bird attack on butterflies was very small. Quite experienced field naturalists commented on its rarity.

In the subsequent search for evidence two promising lines of work have been in progress. At an early stage field experiments were made by offering to tame or wild birds butterflies that were believed to be palatable or distasteful, together with mimics of the latter.

More recently, progress has been made by the discovery that the butterfly wings often show definite marks where they have been nipped by the beak of a bird. In these cases, of course, the butterflies have been fortunate enough to escape. The marks may be so definite that the size and angle of the beak may be measured and a close guess made at the group or even species of bird that caused the injury.

Prof. G. D. H. Carpenter has been associated with these lines of study for many years and in two recent papers*, one prepared from notes left by the late C. F. M. Swynnerton, he brings forward much new evidence on both counts.

On the problem of the relative frequency of beak marks he shows that in more than ten thousand museum specimens of the distasteful genus Euploea, $123(1 \cdot 15$ per cent) showed beak marks on the wings; in more than six thousand African Danain butterflies, also distasteful, 117 (1.05 per cent) had marks ; but in more than seven thousand African Colotes spp., a quite edible genus, only $11(0.15$ per cent) were marked.

* (1) Observations and experiments in Africa by the late C. F. M. Swymnerton on wild birds eating butterflies and the preferences shown. Proc. Linn. Soc. Lon, Session 154, 10-46 (1942).

(2) The relative frequency of beak marks on butterflies of different edibility to birds. Proc. Zool. Soc. Lon. (A), 111, 223-230 (1941).
The inference is, as Prof. Carpenter points out, not that the distasteful species are more frequently bitten by birds, but that, being bitten, they more frequently escape or are allowed to escape.

A comparison was also made between $\mathbf{5 5 0}$ distasteful Danaine models which showed 17 individuals with beak marks, and 340 Nymphaline mimics, of which there was only a single one with a beak mark.

In an appendix to this paper, it is also shown that of 613 distasteful butterflies from all parts of the world which had beak marks, 133 or 21 per cent had evidence of more than one attack, while of 179 edible butterflies with beak marks only 21 , or $11 \cdot 7$ per cent, had evidence of more than one attack. The difference is statistically significant.

Prof. Carpenter's conclusion, which seems to be justified, is that distasteful (aposematic) species are more frequently found with beak marks because they "live to fight another day", owing to not having been eaten by their bird enemies even when they have been seized.

The summary of Swynnerton's field experiments is a mine of interesting information. The main portion deals with the behaviour of birds towards butterflies of different species which were 'planted' in positions visible to the birds but prevented by various means from flying away. Twenty-two such experiments are described and the results are very striking. Time and time again the more distasteful species are either completely neglected, or, even more convincingly, carefully examined at first and then neglected. The more palatable species, on the contrary, were eaten in very high proportions. The distinction between palatable and distasteful is not absolute but comparative, and very hungry birds will eat relatively distasteful species, while replete birds will require to be tempted by a particularly choice morsel. Other things being equal, a hungry bird will eat a large butterfly in preference to a smaller one.

In one example given (Section C, Experiment 1), 84 butterflies were exposed, and after five hours $4: 5$ had been eaten. Among the butterflies were 7 Danains (aposematic), none of which had been touched, and 24 Vanessa cardui, of which 22 had been eaten.

In other experiments the birds were shown to be definitely deceived by mimics of aposematic species.

There is no doubt that a considerable body of evidence has been brought forward to show that birds are important and critical enemies of butterflies, that they have to learn by experience the appearance of distasteful species, and that once having learnt this they are frequently deceived by mimetic resemblance.

\section{UTILIZATION OF GLASS}

$\mathrm{P}$ ROF. W. E. S. TURNER read a paper on "New Uses for Glass" before the Royal Society of Arts on January 20. $\mathrm{He}$ briefly traced through history the development of the use of glass from its main original use for decorative purposes to its everwidening use as an essential material for utilitarian purposes. No period has seen more fruitful advances than the past fifteen years.

Systematic scientific investigation has resulted in providing us with glasses having a density from 2 up to 8 : a coefficient of thermal expansion varying at least thirty-fold ; a range of thermal endurance such 
that objects made from some glasses can be heated to glowing and quenched in water without fracture; a range of load-bearing capacity up to six and even ten-fold; electrical resistance varying up to at least ten thousand-fold; while the non-corrodible character of modern types of glasses is such that it can and has replaced stainless steel, offers resistance to steam at high temperatures and pressure, to strong acids and many liquids which are chemically corrosive of other known materials and is without any action on the most sensitive of physiological, biological and chemical preparations.

Sheet glass is now drawn continuously in the flat state more than one hundred inches wide; plate glass is, by the latest British process, not only rolled continuously some $12 \mathrm{ft}$. wide, but is simultaneously ground and polished on both sides. Thousands of different articles such as bottles, jars, tumblers and drinking vessels of all kinds, even complicated articles like jugs with handles and wine glasses with feet, are now produced entirely by automatic machinery; half a million electric light bulbs per day are turned out by automatic machines and miles of glass tubing of various kinds and diameters. Glass can be converted into flakes and drawn into threads as fine as silk at the speed of some six thousand feet per minute, with numerous uses in the production of yarn and woven textiles, as filtering mediums and for insulating purposes.

The modern processes of tempering glass have tremendously increased its safety factor against breakage and made its use possible against extremes of heat and cold, for transparent pressure chambers, for high-power electric insulators, a base on which to spray a metal for grids to form electric radiators, for the tops of hot stoves, and for general constructional purposes, including doors provided with metal fittings. The combination of layers of glass with very thin layers of transparent plastic materials has given laminated glass for transport vehicles and, when used in multi-layers, bullet-resisting glass, as used in tanks and aeroplanes.

The advances in sealing glass to metals have made possible the construction of metal filament electric lamps, cathode ray tubes and radio valves ; mercury arc rectifiers, in glass envelopes and operating with electrodes at high temperatures, are now in operation in many transformer stations.

Glass can also be coloured for the transmission of light and radiation; colourless glasses will transmit X-rays with high efficiency, whereas lead- and barium-containing glass provides screens for protection against X-rays. Glasses are made with a high transmission for ultra-violet light; and deeply coloured glasses can be made which transmit nothing but ultra-violet light on one hand or infra-red on the other.

\section{FORTHCOMING EVENTS}

(Meeting marked with an asterisk is open to the pitblic)

\section{Saturday, February 6}

NUTRITION SocIETY (at the London School of Hygiene and Tropical Medicine, Keppel Street, London, W.C.1), at 11 a.m. - Conference on "Nutrition in Pregnancy".

BRITISH Rheologists' CldB (at the Royal Society of Arts, John Adam Street, Adelphi, London, W.C.2), at 2.15 p.m.-Dr. R. N. Haward:" "The Extension and Impact Resistance of some Plastic Materials".

Geologists' Assoctation (at the Geological Society, Burlington House, Piccadilly, London, W.1), at 2.30 p.m.-Mr. F. A. Bannister "The Determination of Minerals by X-Ray Methods".
Monday, February 8

INSTITUTION OF ChemicaI ENGINEERS (JOINT MEETING WITH THE

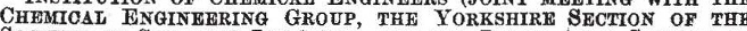
SOCIETY OF CheMtCal INDUSTRY, AND THE LEEDS AREA SECrion OF THE INSTITUTE OF CHEMISTRY) (in the Chemistry Lecture Theatre, The University, Woodhouse Lane, Leeds), at 6 p.m.-Dr. A. H. Jay: "The Application of Crystal Analysis to some Chemical Engineering Materials".

Tuesday, February 9

Royal College of Physicians (at Pall Mall East, London, S.W.1), at 2.15 p.m.-Prof. M. Greenwood, F.R.S.: "Medical Statisticians from Petty to Farr" (Fitzpatrick Lectures, 1).

ROYAL INSTITUTION (at 21 Albemarle Street, London, W.1), at 3 p.m.- Sir Lawrence Bragg, F.R.S.: "The Solid' State", (iii) "Minusminus Compounds"”*

InLUMINATING ENGINEERING Society (at Gas Industry House, 1 Grosvenor Place, London, S.W.1), at 5 p.m.-Contributions on "The Effectiveness of Lighting, its Numerical Assessment", to be followed by a Discussion.

Wednesday, February 10

Royal Society of ARTs (at John Adam Street, Adelphi, London, w.C.2), at 1.45 p.m.-Mr. R. G. Glenday : "Location of Industry".

Royal College of Physicians (at Pall Mall East, London, S.W.1), at 2.15 p.m.-Prof. M. Greenwood, F.R.S.: "Medical Statisticians from Petty to Farr" (Fitzpatrick Lectures, 2).

INSTITUTION OF Electrioal ENGINEERS (INSTALLATIONS SEOTION) (at Savoy Place, Victoria Fmbankment, London, W.C.2), at 5.30 p.m. $\rightarrow$ Discussion on "The Use of Flectricity in relation to Fuel Economy"
(to be opened by Mr. R. H. Rawll).

\section{Friday, February 12}

ROYaL Institution (at 21 Albemarle Street, London, W.1), at 5 p.m.-Dr. G. M. B. Dobson, F.R.S., and Dr. A. R. Meetham: "The Air we breathe in Town and Country".

Saturday, February 13

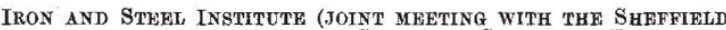
METALLURGical ASSOCIATION, THE SHEFFIELD SOCIETY OF ENGINEERS AND Metallutrgists, aND THE SOUTH YoRKShIRE SECTION OF THE INSTITUTE OF CHEMISTRY) (at the Royal Victoria Station Hotel, Sheffield), at 2.30 p.m.-Mr. H. T. Shirley and Mr, E. Elliott: "A' Critical Consideration of some Applications of the Spectrograph to Steelworks Analvsis".

\section{APPOINTMENTS VACANT}

APPLICATIONS are invited for the following appointments on or before the dates mentioned :

Incturer in Mining--The Principal and Clerk to the Governing Body, Wigan and District Mining and Technical College, Wigan (February 13).

LECTURER IN CheMISTRY - The Principal and Clerk to the Governing Body, Wigan and District Mining and Technical College, Wigan (February 13).

Graduate Master or Mistress to teach Mathematics aND GEogRAPHY in the Harrogate Technical Institute-Mr. W. E. C. Jalland, The Secretary to the Managers. Municipal Offices, Harrogate (February 15).

ChaIr of Mining-The Secretary, The University, Edmund Street, Birmingham 3 (March 1).

INSTRUCTOR IN BEAKEFPING-The Education Officer, County Hall, Wakefleld (March 1).

Sir Dorab Tata Reader in Pharmaceutical Chemistry in the Department of Chemical Technology-'The Registrar, University of Bombay, Bombay, India (April 15)

Hean of the Mining Departuent-The Principal, County Technical College, Mansfield, Notts.

LECTURER IN FLECTRICAL ENGINEFRING-The Clerk to the Governors, South-W'est Essex Technical College and School of Art, Forest Road, Walthamstow, London, F.17.

\section{REPORTS and other PUBLICATIONS}

\author{
(not included in the monthly Books Supplement)
}

Great Britain and Ireland

Ministry of Fuel and Power. Twentieth Annual Report of the Safety in Mines Research Board, 1941. Pp. 28. (London: H.M. Stationery Office.) 18. net.

Other Countries

Bulletin of the American Museum of Natural History. Vol. 80 Art. 6: The Fauna of Papago Springs Cave, Arizona, and a Study of Stockocerus; with Three New Antilocaprines from Nebraska and Arizona. By Morris F. Skinner. Pp. 143-220. (New York: American Museum of Natural History.) 